\title{
Pleomorphic Liposarcoma of the Axilla Metastatic to the Pancreas
}

\author{
Giuseppe Malleo $^{a}$ Stefano Crippa ${ }^{a}$ Stefano Partelli ${ }^{a}$ Paola Capelli ${ }^{b}$ Roberto Salvia ${ }^{a}$ \\ Claudio Bassi ${ }^{a}$ \\ ${ }^{a}$ Department of Surgical and Gastroenterological Sciences, General Surgery B, and the ${ }^{\mathrm{b}}$ Department of Pathology, \\ 'G.B. Rossi' Hospital, University of Verona, Verona, Italy
}

Dear Sir,

Pleomorphic liposarcoma (PLS) is the less common histologic subtype of liposarcoma, with light-microscopic evidence of pleomorphic lipoblasts and a malignant fibrous histiocytoma-like or, less frequently, an epithelioid growth pattern. The epithelioid morphology may be mistaken for other epithelial neoplasms, such as renal or adrenal cortical carcinoma, and differ- ential diagnosis may require ultrastructural analysis [1-3]. PLS is typical of adulthood with a strong predilection for the deep, soft tissues of the extremities, although many other sites (e.g. the retroperitoneum) can be involved. It clinically behaves as a high-grade tumor with elevated metastatic potential and a 5-year survival ranging from 30 to $50 \%$ [1-3]. Here we de- scribe the case of a PLS metastatic to the pancreas observed at our institution in a 30-year-old man. His medical history was significant for a malignant mixed germ cell tumor of the right testis with aspects of immature teratoma, embryonal carcinoma and yolk sac tumor. Right orchiectomy was carried out in 2000, followed by chemotherapy with cisplatin, etoposide

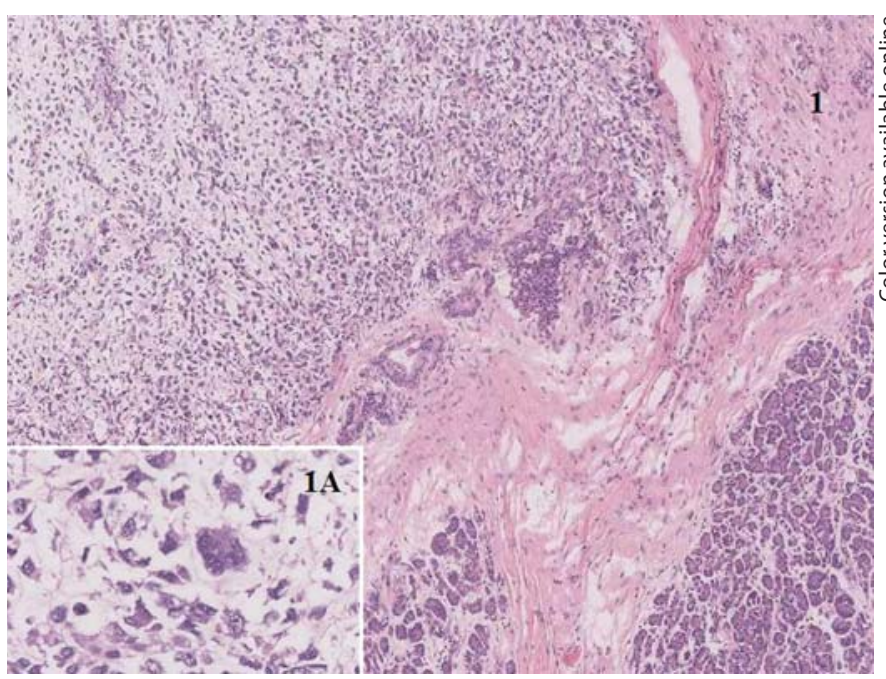

Fig. 1. Representative hematoxylin and eosin-stained section of pancreatic PLS. 1A Particular of a monster cell.

\section{KARGER}

Fax +41613061234 E-Mail karger@karger.ch www.karger.com
(C) 2009 S. Karger AG, Basel

0253-4886/09/0263-0262\$26.00/0

Accessible online at:

www.karger.com/dsu

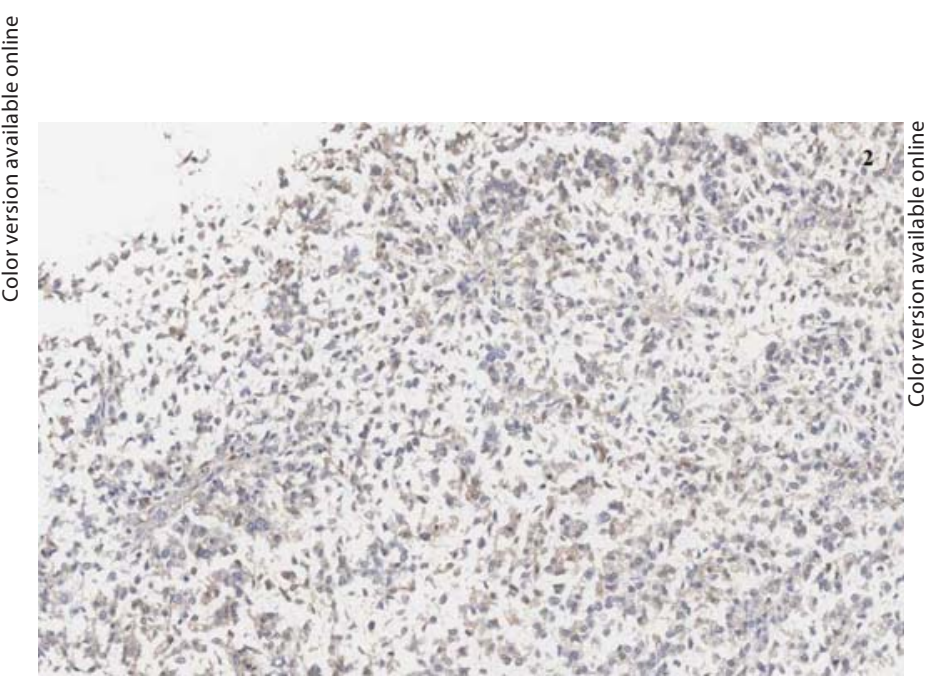

Fig. 2. Immunohistochemical analysis for S-100 protein showing weak positivity in pleomorphic lipoblasts.

Giuseppe Malleo, MD

General Surgery B, ‘G.B. Rossi’ Hospital

P.le L.A. Scuro 10, IT-37134 Verona (Italy)

Tel. +39045812 4060, Fax +390458124826

E-Mail giuseppe.malleo@medicina.univr.it 
and bleomycin. In 2005 the patient underwent excision of a mass in the right axilla, which was shown to be a PLS with focal epithelioid aspects. In particular, TSL/ $\mathrm{CHOP}$ chromosomal rearrangement was negative. Six months later the tumor again recurred in the right axilla, and complete excision was achieved. Pathological examination with ultrastructural analysis confirmed the diagnosis of recurrent PLS. Chemotherapy with epirubicin and isofosfamide, as well as external beam radiotherapy (60 Gy) on the axilla were undertaken.

Follow-up was negative until June 2007, when contrast-enhanced computed tomography revealed a hypodense and hypovascular lesion of $35 \times 40 \mathrm{~mm}$ in the body tail of the pancreas. There was no sign of vascular infiltration, and the patient was referred to our center to undergo surgical resection for what was thought to be a primary pancreatic tumor. Preopera- tive transabdominal contrast-enhanced ultrasonography confirmed the finding, with the lesion being hypoechoic, hypovascular and partially fluid. Tumor markers were negative. Distal pancreatectomy with splenectomy was carried out, frozen section of the resection margins was negative for neoplastic cells. The postoperative course was uneventful, and the patient was discharged after 7 days. Macroscopic examination revealed a relatively well-demarcated, multinodular tumor measuring $45 \mathrm{~mm}$ in length, whitish to brown-yellow on sectioning. At the microscopic examination, the lesion contained large lipoblasts in a background of a high-grade pleomorphic sarcoma with epithelioid aspects (fig. 1, 1A). Infiltration of peripancreatic tissues as well as of the pancreatic parenchyma was demonstrated. Regional lymph nodes were negative. The mitotic rate was 10/10 HPF. Immunohistochemical analysis for S-100 protein was weakly positive (fig. 2). No other adjuvant therapy was undertaken. After 20 months, the patient remains asymptomatic, no further recurrence was observed during routine follow-up.

Few cases of pancreatic liposarcoma have been reported so far $[4,5]$, and - to the best of our knowledge - this is the first description of a PLS metastasizing to the pancreas. According to current literature, patient age $\geq 60$ years, high histologic grade, deep situation, tumor size $\geq 10 \mathrm{~cm}$, mitotic rate $\geq 10 / 10 \mathrm{HPF}$ and epithelioid morphology are associated with a poor prognosis [3]. As a final consideration, primary germ cell tumors with sarcomatous metastases have been described [6]. In this specific case, however, a relationship between the mixed germ tumor of the testis and the subsequent development of a PLS may just be speculated.

\section{References}

1 Gebhard S, Coindre JM, Michels JJ, Terrier P, Bertrand G, Trassard M, Taylor S, Château $\mathrm{MC}$, Marquès B, Picot V, Guillou L: Pleomorphic liposarcoma: clinicopathologic, immunohistochemical, and follow-up analysis of 63 cases. Am J Surg Pathol 2002;25:601616.

-2 Downes KA, Goldblum JR, Montgomery EA, Fischer C: Pleomorphic liposarcoma: a clinicopathologic analysis of 19 cases. Mod Pathol 2001;14:179-184.

3 Hornick JL, Bosenberg MW, Mentzel T, McMenamin ME, Oliveira AM, Fletcher CD Pleomorphic liposarcoma. Clinicopathologic analysis of 57 cases. Am J Surg Pathol 2004;28:1257-1267.

4 Carboni F, Ettorre GM, Lorusso R, Lepiane P, Santoro R, Mancini P, Di Matteo FM, Santoro E: Isolated pancreatic metastasis of extremity myxoid liposarcoma: report of a case. Jpn J Clin Oncol 2006;36:662-664.
5 Dodo IM, Adamthwaite JA, Jain P, Roy A, Guillou PJ, Menon KV: Successful outcome following resection of a pancreatic liposarcoma with solitary metastasis. World J Gastroenterol 2005;11:7684-7685.

6 Malagon HD, Valdez AM, Moran CA, Susters S: Germ cell tumors with sarcomatous components: a clinicopathologic and immunohistochemical study of 46 cases. Am J Surg Pathol 2007;31:1356-1362. 